TRANSLATIONAL RESEARCH IN VETERINARY SCIENCE

\title{
Equine Back Disorders: A comparative study between palpation and radiographic findings
}

\author{
Radomir Henklewski* \\ Centre of Veterinary Sciences, Inter-University Centre of Veterinary Medicine, \\ Nicolaus Copernicus University, Toruń, Poland
}

\section{${ }^{\star}$ Corresponding author:}

Dr n. wet. Radomir Henklewski, Centre of Veterinary Sciences, Inter-University Centre of Veterinary Medicine, Nicolaus Copernicus University, ul. Gagarina 7, 87-100 Toruń, Poland Email: radomir.h@gmail.com

\begin{abstract}
The reason for performing this study was to investigate relationship between presence or absence of clinical signs of back problems with radiological findings and also to determine the prevalence of concurrent osseous pathology. Forty-four horses underwent clinical and radiological investigation of thoracolumbar spine. Results were recorded. Statistical analysis was performed to determine relationships between age, gender, work discipline, clinical and radiological features. The most common pathological finding was kissing spines syndrome. There was significant association between age, gender and work discipline and prevalence of pathological and radiological findings. X-rays revealed that horses with clinical signs of back problems were more likely to have osseous changes.
\end{abstract}


Radiological examination should be always critically interpreted in a connection to the clinical sings in order to establish a diagnosis of a patient.

Keywords: horse; back problems; radiography; kissing spines thoracolumbar; osseous pathology.

\section{Introduction}

Pain originating in thoracolumbar spine is a common cause of training problems and poor performance in horses. Variety of osseous pathological changes can be found on radiographic and scintigraphic images obtained from clinically normal horses as well it could be no signs of pathology in bony structures in horses with thoracolumbar pain [1]. That is why the diagnosis of that body region is challenging. The most common pathological finding is impinging and overriding of the spinous processes (SPs). Not always it is causing clinical signs $[2,3]$. Thoracolumbar pain can be correlated with soft tissues (muscles, tendons) and osseous tissues (spinous processes, facet joints). Ensuring some appropriate examination conditions (e. g. flat and slip-resistant surface, quiet environment) is equally significant as a character of the patient, its sensitivity to external stimuli, age etc. The reason of performing this study was to investigate relationship between presence or absence of clinical signs of back problems with radiographic findings and also to determine the prevalence of concurrent osseous pathology.

\section{Material and methods}

Animals

Forty-four horses underwent clinical and radiographic investigation of thoracolumbar spine were investigated. Gender, age and work discipline were recorded as well as results of clinical and radiographic examination 
were determined. A total of 44 Horses were investigated at the age between 0,5 to 18 years, with an average of 8 years. Three groups: consisted of mares $(n=12 ; 27,3 \%)$, geldings $(n=22 ; 50 \%)$ and stallions $(n=10 ; 22,7 \%)$ were investigated. Work discipline was categorized as sport discipline including: dressage, show jumping, racing events (including flat racing, harness racing and steeplechase) and general purposes. Six horses $(13,6 \%)$ were not used in work yet; sixteen horses $(36,4 \%)$ were used for pleasure/ general purposes (with irregular training); twenty-two animals (50\%) were used in sport disciplines mentioned above. Initially patients were examined for posture abnormalities, muscle asymmetry, external wounds and other physical anomalies that could have affected the clinical examination. Then the examination at rest was performed including palpation of the back muscles and evaluation of dorsoventral and lateral mobility of the back. In healthy horses such movements and palpation should not induce pain, tension of muscles and defensive behaviours [3, 4]. All results were recorded.

\section{Radiographic methodological procedure}

Radiographic examination of laterolateral projection was performed which is not easy to obtain due to the thickness of the tissue. Therefore, cassette holder that was made for this study was used to eliminate movements of the cassette during the X-ray. Horses stood squarely on four feet on non-slippery surface to prevent lateroflexion or rotation of the spine. Head and neck were positioned at the level of the shoulder joint because in previous study it was proven that level at which the head is held has influence the measured distance between next dorsal spinous processes from Th8 to Th15 [5]. The performed radiographic examinations were either left lateral to right lateral or right lateral to left lateral. The exposure values were 79-89 $\mathrm{kV}$ and $0.18-0.16 \mathrm{mAs}$ depending on a horse's size. The cassette (14x17 Regius Konica Minolta Medical and Graphic) was held (using a holder) as closely to the horse as is possible to minimize distortion of the images by magnification. X-ray beam was centered $15 \mathrm{~cm}$ 
below the surface of the back line. Radiographs were obtained with equipment Konica Minolta Regius model 110 S, Simens Vertix 3D (150 kV, 500 $\mathrm{mAs}, 75 \mathrm{~kW}$ ). Images' evaluation included measuring distances between next dorsal spinous, evaluating margins of SPs and its morphology. The evaluation of images were performed by the vertebrae Th12 due to their characteristic morphology as vertebrae anticlinales. The scale presented by Zimmerman and co-workers in 2011 and 2012 were also used for evaluation $[6,7]$. The statistical analysis of assembled results was performed with a STATISTICA PL 10.0 programme using the chi-squared test. The significance was set at $\mathrm{P} \leq 0,05$.

\section{Results}

Patients' data collected during this study including gender, work discipline and the results of radiographic and clinical examination are summarized in Table 1. The most frequent osseous pathology identified at the thoracolumbar radiographs was impinging and overriding of the SPs. It was identified in $50 \%$ of pathologically changed X-rayed spines.

Depending on the age of the patients, they were divided in sub-groups of younger individuals (under 8 years) consisting of 26 horses and older individuals (over 8 years) consisting of 18 horses. The age is a statistically important factor influencing radiographic results $(\mathrm{p}=0,0359)$ showing that older horses were more likely to have pathological findings on thoracolumbar X-rays. Six of all examined horses were not used in work and remaining thirty-eight were used either in sport disciplines or for general purposes. It is also statistically important factor influencing radiographic changes on thoracolumbar views ( $\mathrm{p}=0,02295)$. However, there was no statistical difference between horses undergoing regular training for particular sport disciplines and horses used for general purposes with infrequent training $(\mathrm{p}>0,05)$.

The study group was also subdivided in four sub-groups depending on the results of clinical (mainly palpation of thoracolumbar spine) and radiographic examination. Results are summarized in Table 2 showed 
that only $4,5 \%$ of horses that had no osseous pathology on a thoracolumbar X-ray showed clinical signs of pain. It was supposed that soft tissues (muscles, tendons) were responsible for painful reaction but no further examination was performed. $36,4 \%$ of the examined group were clinically and radiographically healthy horses. The same numerous was the group of patients that had pathological findings on thoracolumbar X-rays but showed no clinical signs of pain. Positive findings on radiographic examination and palpation correlating with the clinical signs were identified in $22,7 \%$ of examined horses. In this it has proven too that positive clinical examination and palpation results are statistically important factor correlated with pathological findings on radiographic views. $(\mathrm{p}=0,0452)$. Gender was considered as statistically important factor influencing pathologi-

Table 1. Data of forty-four horses that underwent radiographic and clinical examination of thoracolumbar spine

\begin{tabular}{|l|c|c|}
\hline \multicolumn{1}{|c|}{ Features } & $\begin{array}{c}\text { Number } \\
\text { of horses }\end{array}$ & Percentage [\%] \\
\hline Gender & 12 & 27,3 \\
\hline Mare & 10 & 22,7 \\
\hline Stallion & 22 & 50 \\
\hline Gelding & \multicolumn{2}{l}{} \\
\hline Work discipline & 6 & 15,9 \\
\hline None & 16 & 36,4 \\
\hline General purposes/ pleasure & 20 & 45,7 \\
\hline Sport disciplines & 32 & 72,7 \\
\hline Results of palpation of the back & 12 & 27,3 \\
\hline No pain, defensive reaction, muscle tension & \multicolumn{1}{|l|}{} \\
\hline Painful, defensive reaction and muscle tension & 22 & 48,8 \\
\hline Results of radiographic examination & 11 & 24,4 \\
\hline Impinging and overriding of the SPs & 7 & 15,5 \\
\hline Exosthosis & 2 & 4,5 \\
\hline Desmopathy & 3 & 6,8 \\
\hline Osteolysis & & \\
\hline Cysts & \multicolumn{1}{|l|}{} \\
\hline
\end{tabular}


cal changes of bony structures on X-ray images pointing the geldings as more prone to develop such changes $(\mathrm{p}=0,0158)$. Influence of particular sport discipline was not investigated because number of horses in each discipline was too low to compare it statistically which was the limitation of this study.

Radiographs were evaluated using grading system scale to objectify the results according to Zimmerman et al. 2011 procedures [6]. Number of points for each horse was determined as the result of the most pathologically changed SP. Evaluation was blinded (made by the same experienced veterinarian with no access to results of clinical examination). Then data conserving the same patient were combined and results are showed on Figure 1. Horses that had clinical signs of pain and pathological findings on thoracolumbar radiographs had higher notes in grading system scale showing that these changes were more pronounced in these patients [1].

\section{Discussion}

This study has shown that the clinical signs of pain during back palpation are correlated with more pronounced changes on radiographic examination $[3,7-9]$. However, it is necessary to conduct a critical and thorough evaluation of obtained X-rays in comparison to clinical examination in or-

Table 2. Summary of clinical examination (palpation of thoracolumbar spine) and radiographic examination. Signs of pain, defensive behavior or tension of muscles in palpation and any signs of osseous pathology in X-ray views were considered as positive (+)

\begin{tabular}{|l|c|c|c|c|}
\hline $\begin{array}{c}\text { Examination } \\
\text { result }\end{array}$ & $\begin{array}{c}\text { X-RAY(+) } \\
\text { PALPATION (+) }\end{array}$ & $\begin{array}{c}\text { X-RAY (-) } \\
\text { PALPATION (+) }\end{array}$ & $\begin{array}{c}\text { X-RAY (+) } \\
\text { PALPATION (-) }\end{array}$ & $\begin{array}{c}\text { X-RAY (-) } \\
\text { PALPATION (-) }\end{array}$ \\
\hline $\begin{array}{l}\text { Number } \\
\text { of horses }\end{array}$ & 10 & 2 & 16 & 16 \\
\hline $\begin{array}{l}\text { Percentage } \\
{[\%]}\end{array}$ & 22,7 & 4,5 & 36,4 & 36,4 \\
\hline
\end{tabular}




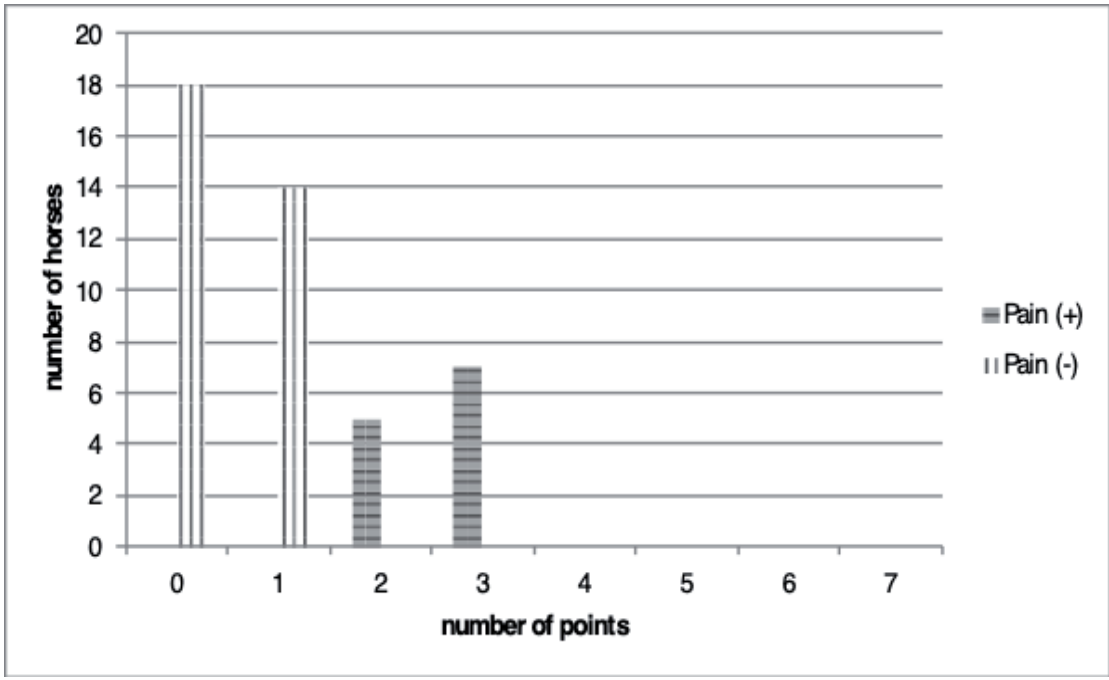

Figure 1. Results of evaluation of obtained X-rays involving grading system scale

der to avoid over-diagnosis. Implementation of grading system scale may be as useful as standardizing the technique of performing radiographic examination to objectively assess obtained radiographic views.

Radiographic examination is an easy, low-cost and non-invasive technique which can be performed in ambulatory practice and used in back problems diagnosis. It is crucial to remember about the appropriate preparation of a patient, the use of sedatives (if required), elimination of any unnecessary equipment and reduction of patient's movements. Due to the thickness of the tissue, projections of this body region are difficult to perform.

The study has shown that pathological changes of SPs are more pronounced among older horses. The older the horse, the longer its use in work disciplines, often resulting in pathological back changes [10]. In this study horses with infrequent training, used for general purposes and for riding schools did not differ from horses used in sport disciplines. That result is unexpected because of the common opinion that horses used for 
general purposes, especially in riding schools involving many inexperienced riders and lack of regular training schedule, are more prone to develop all kinds of musculoskeletal abnormalities.

\section{Conclusions}

In conclusion, the study demonstrates that clinical examination as well as correctly performed radiographic examination and objectively evaluation of images are essential for back problem diagnosis. Study concluded that the older horses were more likely to have pathological findings on thoracolumbar X-rays.

\section{Acknowledgment}

This work was based on student project of Agnieszka Florczyk which was carried out under the supervision of the author.

\section{References}

1. Cousty M, Retureau C, Tricaud C, Geffroy O, Caure S. Location of radiological lesions of the thoracolumbar column in French trotters with and without signs of back pain. Vet Rec. 2010; 166.: 41-45.

2. Erichsen C, Eksell P, Widström C, Roethlisberger Holm K, Johnston C. Scintigraphic evaluation of the thoracic spine in the asymptomatic riding horse. Vet Radiol Ultras 2003; 44: 330-338.

3. Ranner W, Gerhards H, Klee W. Diagnostic validity of palpation in horses with back problems. Berliner und Münchener Tierärztliche Wochenschrift. 2002; 115: 420.

4. Martin Jr B. B., Klide A. M.: Physical examination of horses with back pain. The Vet clin North Am Eq pract. 1999; 15: 61.

5. Berner D, Winter K, Brehm W, Gerlach K. Influence of head and neck position on radiographic measurement of intervertebral distances between thoracic dorsal spinous processes in clinically sound horses. Eq Vet J 2012; 44: 21-26. 
6. Zimmerman M, Dyson S, Murray R. Comparison of radiographic and scintigraphic findings of the spinous processes in the equine thoracolumbar region. Vet Radiol Ultras 2011; 52: 661-671.

7. Zimmerman M., Dyson S., Murray R.: Close, impinging and overriding spinous processes in the thoracolumbar spine: The relationship between radiological and scintigraphic findings and clinical signs. Eq Vet J 2012; 44: 178-184.

8. Holmer M, Wallanke B, Stadtbäumer G. Radiographs findings in back region of 295 clinically healthy Warmblood horses. Röntgenveränderungen an den Dornfortsätzen von 295 klinisch rückgengesunden Warmblutpferden. Pferdeheilkunde 2007; 23: 507-511.

9. Butler JA, Colles CM, Dyson SJ, Kold SE, Poulos PW. Clinical radiology of the horse. Wiley-Blackwell 2011.

10. Henson FMD. Equine back pathology: diagnosis and treatment. Wiley-Blackwell 2009. 